\title{
Monoterpene and Phenolic Compound Concentrations in Water-Stressed Red Pine Inoculated with Sphaeropsis sapinea
}

\author{
J. T. Blodgett and G. R. Stanosz
}

Department of Plant Pathology, University of Wisconsin, 1630 Linden Drive, Madison 53706-1598. Accepted for publication 25 November 1997.

\begin{abstract}
Blodgett, J. T., and Stanosz, G. R. 1998. Monoterpene and phenolic compound concentrations in water-stressed red pine inoculated with Sphaeropsis sapinea. Phytopathology 88:245-251.

Changes in monoterpene and phenolic compounds resulting from water stress and colonization by Sphaeropsis sapinea were examined for 9- and 11-year-old red pine trees in a plantation and 3-year-old seedlings in a growth chamber. Four treatments were assigned at random to individual trees in the field: no treatment, herbicide to kill surrounding weeds, supplemental water, and both herbicide and supplemental water. In the growth chamber, seedlings were either not watered (water stressed) or watered daily (nonstressed). Shoots were inoculated with agar plugs colonized with either S. sapinea isolates of morphotype A and

$\delta$-3-carene ( 1 to $5 \%$ of the total). Shoots inoculated with isolates of morphotype A had more severe symptoms and produced higher concentrations of monoterpenes in both experiments compared with the controls. In the growth chamber, inoculations with isolates of morphotype A caused higher concentrations of phenolics compared with the controls. In the field experiment, monoterpenes increased in quantity only in shoots of stressed trees inoculated with isolates of morphotype A. Isolates of morphotype B caused few symptoms and did not alter monoterpene concentrations. Increases in monoterpenes do not appear to be involved in the response to infection by morphotype A in nonstressed trees, and the role of phenolics is unclear. However, these results are consistent with previous observations that monoterpenes may be involved in the differences in aggressiveness between morphotypes on red pine.
\end{abstract} $B$ (field) or only isolates of morphotype A (growth chamber). Nine monoterpenes were detected in tissue extracts; the most common were $\alpha$-pinene (59 to $74 \%$ of the total), $\beta$-pinene (13 to $33 \%$ of the total), and
Additional keywords: Diplodia pinea, drought, Pinus resinosa.
Severe damage to two- and three-needled pines caused by Sphaeropsis sapinea (Fr.:Fr.) Dyko \& Sutton in Sutton (syn. Diplodia pinea (Desmaz.) J. Kickx fil.) throughout the world is associated with predisposing stresses including water stress $(2,26$, $32,33)$. Controlled studies on the effects of host water stress on disease development have been conducted on other hosts. However, either water stress was severe $(-3.0 \mathrm{MPa}$ or lower) or data were not statistically analyzed $(1,8,29,40)$. More recently, studies conducted in a greenhouse, a growth chamber, and a plantation demonstrated that moderate water stress (above $-1.9 \mathrm{MPa}$ ) enhanced shoot colonization of red pine (Pinus resinosa Aiton) by $S$. sapinea $(4,5)$.

There are two recognized morphotypes of S. sapinea (34). Morphotypes are morphologically distinguishable groups of individuals within a species with unknown or no taxonomic significance (15). The A morphotype of $S$. sapinea is more aggressive in colonizing red pine than the B morphotype (7). Moderate water stress increases severity of disease on red pines inoculated with isolates of morphotype A but not of morphotype B (4).

Conifers can respond to fungal colonization by forming resinous lesions in the phloem and sapwood around the infection sites. These resinous lesions contain high concentrations of secondary metabolites (31), including monoterpene and phenolic compounds $(24,35)$. A defensive function has been suggested for the secondary metabolites elicited in response to pathogen invasion of pines $(3,41)$. Monoterpenes and phenolics are the main classes of chem-

Corresponding author: J. T. Blodgett

E-mail address: Blodgett@landbou.uovs.ac.za

Publication no. P-1998-0122-01R

(C) 1998 The American Phytopathological Society icals associated with the resistance of many pine species to pathogens and insects $(19,28,35,38,39)$. These compounds can increase in quantity and change in quality in response to mechanical damage and fungal invasion. They occur in high concentrations in conifer species (up to hundreds of milligrams per gram, dry weight) and have fungistatic properties at concentrations observed in pines and other conifers $(16,24,25,35)$. They have been found to have fungistatic effects on various disease-causing fungi of pines, including the root rot pathogen, Heterobasidion annosum (Fr.:Fr.) Bref. (14,23); stain fungi, including Leptographium spp. (25) and Ophiostoma spp. (35); the needle blight pathogen, Dothistroma septospora (Doroguine) Morelet (12); and the shoot blight and canker pathogen, S. sapinea (9).

The active defensive response may decrease under host stress, resulting in lower concentrations of these chemicals and greater disease severity $(11,24)$. In several conifer species, lower levels of phenolic production and increased colonization by Armillaria ostoyae (Romagnesi) Herink have been attributed to reduced light and low nitrogen levels (11). Lower concentrations of both monoterpenes and phenolics and increased colonization by Leptographium terebrantis S. J. Barras and T. J. Perry were attributed to reduced light (24). However, little research has been conducted on the qualitative effects of water stress on concentrations of monoterpenes and phenolics of pines challenged by canker diseases, such as that caused by $S$. sapinea.

Field and growth chamber experiments were conducted to examine changes in the concentrations of monoterpenes and phenolics of red pine trees in response to water stress and colonization by $S$. sapinea. The purpose of these experiments was to explore the potential role of these compounds in restricting colonization by both aggressive and nonaggressive isolates of this pathogen. These studies also examined host susceptibility resulting from environmental stress. It was hypothesized that when 
pines were challenged by $S$. sapinea, these chemicals would increase in concentration or change in composition in nonstressed trees but that these changes would be inhibited in stressed trees. The objectives of this study were (i) to make quantitative estimates of individual monoterpenes and total phenolics present in red pine, (ii) to determine the effects of moderate water stress and colonization by $S$. sapinea on red pine monoterpenes and phenolics, and (iii) to assess differences in chemical responses of this host to colonization by the $S$. sapinea morphotypes. The null hypotheses tested were (i) concentrations of monoterpenes (both quantity and quality) and phenolics (quantity) do not change in red pine because of water stress or colonization by S. sapinea, and (ii) concentrations of these chemicals do not differ when challenged by A or B isolates.

\section{MATERIALS AND METHODS}

Plant material from the field. A 9-year-old red pine plantation was selected in 1992 in Adams County, Wisconsin, and the experiment was repeated in 1994. Trees were the same as those used in our previous study (5).

Host water potential was manipulated by herbicide applications to control competing vegetation and by supplemental water. Four treatments were assigned at random to individual trees: no treatment, herbicide to kill surrounding weeds, supplemental water, and both weed removal by herbicide and supplemental water. In early July of each year, the herbicide glyphosate (Monsanto, St. Louis, MO) was applied in accordance with label directions within a $1.8-\mathrm{m}$ radius around the experimental trees 3.5 weeks before branches were inoculated. Water (67 liters per tree) was applied within a $0.9-\mathrm{m}$ radius around sample trees twice per week. Watering started in mid-July, 2 weeks before branches were inoculated.

Six treatments were assigned at random to separate branches on each tree. These included inoculation with one of either two A (A1 and A2) or two B (B1 and B2) morphotype single-spore iso-

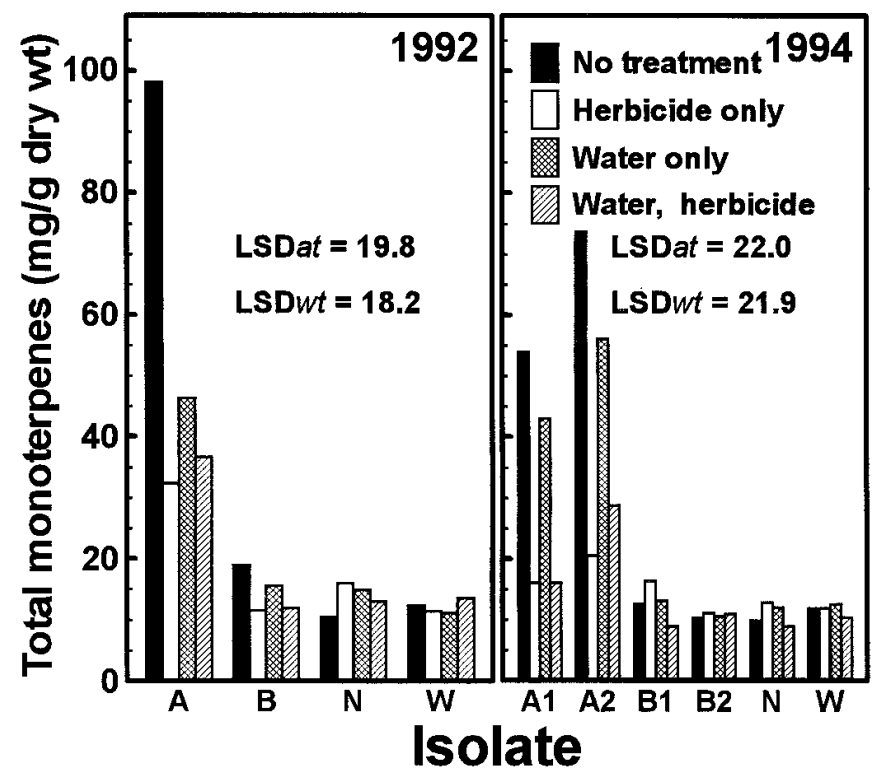

Fig. 1. Total monoterpenes measured after 4 weeks on wounded red pine (Pinus resinosa) trees inoculated with agar plugs colonized by A and B isolates of Sphaeropsis sapinea. Five trees were used per treatment each year. Inoculation treatments include two $\mathrm{A}$ and two $\mathrm{B}$ isolates and both nonwounded (N) and wounded (W) controls for each tree. In 1992, the two A isolates and the two B isolates were combined into composite samples by morphotype. LSD = Fisher's least significant differences for separating the means at $P=0.05$. LSDat is used for means of branch treatments across (for different) tree treatments. LSDwt is used for means of branch treatments within the same tree treatment. lates, a wounded control, or a nonwounded control. The isolates were collected from red and jack ( . banksiana Lamb.) pines in Wisconsin and Minnesota and are the same single-spore isolates (so designated) used in our previous studies (4-7).

Branches were inoculated by procedures described previously (7). A wound, $3 \times 1.5 \mathrm{~mm}$, was made by removing a needle fascicle with a scalpel cut flush to the stem base approximately $3 \mathrm{~cm}$ below the shoot apex. A plug of colonized $1.5 \%$ water agar (WA; Difco, Detroit, MI) $4 \mathrm{~mm}$ in diameter was placed fungus side down on each wound. Noncolonized WA plugs were applied to wounded controls. Parafilm (American National Can, Chicago, IL) was wrapped around each shoot, at the inoculation site, for 7 days.

Four weeks after inoculation, treated shoots were collected from five randomly selected trees of each tree treatment. After needles were removed, segments that included the stem from 1 to $7.5 \mathrm{~cm}$ below the shoot apex were cut. A small amount of each segment was removed to determine recovery success of $S$. sapinea (5). The remainder of the shoot segments were stored at $-80^{\circ} \mathrm{C}$ for later analyses of monoterpene and phenolic concentrations. In 1992, the segments from a tree inoculated with isolates of the same morphotype were combined into a single sample. In 1994, each segment was processed as a separate sample.

Plant material from the growth chamber. A growth chamber experiment was conducted at the University of Wisconsin-Madison Biotron. In April, dormant, 2-year-old red pine nursery seedlings were transplanted into Tall One Treepots (Stuewe \& Sons, Corvallis, OR), which are approximately $10 \times 10 \times 36 \mathrm{~cm}$. A soil $\operatorname{mix}(1: 1, \mathrm{vol} / \mathrm{vol})$ of Plainfield sand from a red pine plantation and Fafard growing mix no. 2 (Conrad Fafard, Inkerman, New Brunswick, Canada) was used. For their third growing season, seedlings were placed in a cold-frame and allowed to harden before the experiment was initiated. Mean stem height after the third growing season was $21.6 \pm 0.4 \mathrm{~cm}$ (standard error).

In February, seedlings were moved into a greenhouse. Artificial light supplemented natural light (supplemented photon flux density averaged $118 \mu \mathrm{E} \mathrm{s}^{-1} \mathrm{~m}^{-2}$ ) to provide a 16-h photoperiod, and all seedlings were initially watered to field capacity every 3 days. After 26 days, seedlings were either watered to field capacity daily (nonstressed) or not watered at all (stressed) for the rest of the experiment (33 days).

After 1 week under the different watering regimes, seedlings were moved into a growth chamber. The average environmental conditions of the growth chamber were as follows: temperature (day $25^{\circ} \mathrm{C}$, night $20^{\circ} \mathrm{C}$ ), relative humidity (day $81 \%$, night $95 \%$ ), light (photon flux density $790 \mu \mathrm{E} \mathrm{s}^{-1} \mathrm{~m}^{-2}$ with a 40-min step up and step down of intensity on each end of a day of $20 \mathrm{~min}$ at 55 and $268 \mu \mathrm{E} \mathrm{s}^{-1} \mathrm{~m}^{-2}$ ), and a day length of $14 \mathrm{~h}$. Predawn needle water potentials $\left(\psi_{\mathrm{PD}}\right)$ were measured every 3 days with a pressure bomb (37) from 20 inoculated seedlings that were randomly placed among the seedlings used for chemical analyses. Five seedlings per treatment combination (watering regime and isolate) were used to determine $\psi_{\mathrm{PD}}$.

After 2 weeks in the growth chamber, elongating shoots were inoculated with isolates A1 and A2 as described in the field experiment, except that wounds were made approximately $2 \mathrm{~cm}$ below the shoot apex and shoots at the inoculation sites were wrapped with Parafilm for 4 days. Noncolonized WA plugs were applied to wounded controls. Five seedlings per watering regime and isolate combination and five wounded and nonwounded controls for each watering regime were used in each of two separate (separated by 2 weeks) completely randomized trials (80 seedlings total).

Symptom severity, expressed as the distance along the stem from the inoculation site to the farthest proximal point at which necrotic needles were observed, was measured at 12 days. Resin flow from the wound (no resin off the wound site, resin less than $3 \mathrm{~mm}$ from the wound site, or resin $3 \mathrm{~mm}$ or farther from the 
wound site) also was recorded at 12 days after inoculation. Two consecutive 6-cm-long segments (starting at the shoot apex) were cut from the stem. Their needles were removed, and they were stored at $-80^{\circ} \mathrm{C}$ for later analyses of monoterpene and phenolic concentrations. The first (apical) segment included the inoculation site and, if present, the resulting symptomatic tissues. The second segment comprised nonsymptomatic tissues. Expression of symptoms by similarly inoculated red pine shoots in earlier studies $(4,7)$ demonstrated the presence of $S$. sapinea, as confirmed by recovery results that gave strong positive correlations between symptom expression and recovery of this pathogen. Therefore, we believe the use of these segments allowed comparison of colonized and noncolonized tissues on the same hosts, which are subsequently referred to as such.

Analyses of shoot segments. All frozen shoot segments were ground in a Wiley mill with a 20 -mesh screen and were again stored at $-80^{\circ} \mathrm{C}$. Monoterpene and phenolic compounds were extracted by using modifications of the procedures described by Klepzig et al. (24). Compounds were first extracted for $24 \mathrm{~h}$ at $25^{\circ} \mathrm{C}$ in $10 \mathrm{ml}$ of analytical-grade pentane containing $0.1 \%$ (vol/ vol) para-cymene (99\%) (Aldrich, Milwaukee, WI) and then for $24 \mathrm{~h}$ at $25^{\circ} \mathrm{C}$ in $10 \mathrm{ml}$ of $50 \%$ methanol and water (vol/vol). Extracts were filtered through Whatman no. 44 filter paper (Whatman International, Maidstone, England). Pentane extracts were analyzed for monoterpenes, and methanol-water extracts were analyzed for phenolics. Para-cymene was used as an internal standard in monoterpene detections because it is structurally similar to the other monoterpenes and does not occur at detectable concentrations in red pine.

The concentrations of the major monoterpenes of red pine were estimated by gas-liquid chromatography (GLC) and identified by retention times with standards obtained from Aldrich. GLC was performed by using a modification of the procedures of Raffa and Steffeck (36). A gas chromatograph with a flame ionization detector (model GC-9A; Schimadzu Scientific Instruments, Columbia, MD) and a $25-\mathrm{m} \times 0.25-\mathrm{mm}$ capillary column (no. 4839; Alltech, Deerfield, IL) were used. Oven temperature was set at $60^{\circ} \mathrm{C}$ and injector and detector temperature at $220^{\circ} \mathrm{C}$; the carrier gas was helium at $30 \mathrm{~cm} \mathrm{~s}^{-1}$ with a methane retention time of $84 \mathrm{~s}$. Compositions of extracts were quantified by peak integration with the Shimadzu C-R3A digital integrator and relative response to the internal standard.

Total phenolic concentrations were estimated by spectrophotometry $(20,22)$. Jorgensen (19) previously showed that pinosylvin is the main extractable phenolic compound of red pine. The extracts $(200 \mu \mathrm{l})$ were diluted with $2 \mathrm{ml}$ of distilled water. One milliliter of 2.0 N Folin \& Ciocalteu's phenol reagent (Sigma, St. Louis, MO) and $5 \mathrm{ml}$ of $20 \% \mathrm{Na}_{2} \mathrm{CO}_{3}$ were added, and tubes were shaken. Absorbencies were measured at $735 \mathrm{~nm}$ after $20 \mathrm{~min}$ at $25^{\circ} \mathrm{C}$. Total phenolic concentrations $(\mathrm{mg} / \mathrm{g}$, dry weight) were calculated on the basis of standard concentrations of tannic acid (Sigma). Standards gave a consistent positive relationship with absorbance throughout the working range $(P<0.001, r=0.992)$.

Statistical analyses. For the field experiment, a split-plot model was used with a tree as a whole plot and the branches as the subplots. Concentrations of total monoterpenes and phenolics were analyzed by two-factor analyses of variance with interactions. Factors used as main effects were tree treatment and branch treatment. Concentration data were analyzed with raw data and $\ln (x+1)$ transformed data. Similar probabilities were calculated and the same conclusions were made for each, so results are reported for the nontransformed data. If significant differences $(P \leq 0.05)$ were found, means were separated by Fisher's least significant difference (LSD) at $P=0.05$. Two LSD values were determined for concentration data because of the experimental designs (30). LSDat was used to separate means for branch treatments across tree treatments, and LSDwt was used to separate means for branch treatments within the same tree treatment. Simple linear regression was used to analyze relationships between symptom severity and chemical concentrations. Both analyses of variance (with the general linear model procedure) and linear regression analyses were performed with Minitab for Windows software, release 10.2 (Minitab, State College, PA).

Analyses of data collected for the growth chamber experiment were similar to those described above with the following exceptions. Predawn needle water potentials and symptom severity were analyzed by three-factor analyses of variance with interactions. Factors used as main effects were watering regime, inoculation treatment, and trial. Concentrations of total monoterpenes and phenolics were analyzed by four-factor analyses of variance with consecutive shoot segments as the fourth factor. Again, two LSD values were determined for concentration data because of the experimental designs (30). LSDwt was used to separate means within a treatment combination at different distances, and LSDat was used to separate means across treatment combinations. Fisher's exact test was used to analyze ratings of resin flow from the stem wounds in relation to the combined inoculation and water treatments. The expected frequencies used were $(S \times C) / N$, where $S$ is the number of observations for a combined inoculation and water treatment, $C$ is the total number of observations in the resin flow category of interest, and $N$ is the total number of observations. This test was performed with SAS software, release 6.09 (SAS Institute, Cary, NC).

\section{RESULTS}

Plant material from the field. There were significant effects of tree treatment on $\psi_{\mathrm{PD}}$ and of both tree treatment and branch treatment on symptom severity (5). Nontreated trees were more water stressed and had more severe disease development than trees in the herbicide, water, or combined herbicide and water treatments. Isolates of morphotype A were more aggressive than isolates of morphotype B for all tree treatments. Also, disease was more severe in 1992 than in 1994.

The amounts of total monoterpene differed in response to tree treatment and branch treatment (Fig. 1). Concentrations of monoterpenes in shoots from nontreated (more water-stressed) trees were higher than in shoots from the herbicide and water treatments in both years $(P=0.028$ for tree treatments in 1992, and $P=$ 0.008 in 1994). Branches inoculated with isolates of morphotype A produced more monoterpenes than branches of the same tree treatments inoculated with isolates of morphotype B $(P<0.001$

TABLE 1. Retention times and correlations of individual monoterpenes to total monoterpene in Sphaeropsis sapinea-inoculated red pine (Pinus resinosa) shoots

\begin{tabular}{|c|c|c|c|c|}
\hline \multirow[b]{2}{*}{ Compound } & \multirow{2}{*}{$\begin{array}{l}\text { Retention } \\
\text { time } \\
(\mathrm{min})\end{array}$} & \multicolumn{3}{|c|}{ Correlation coefficients $^{\mathrm{a}}$} \\
\hline & & $1992^{\mathrm{b}}$ & $1994^{\mathrm{b}}$ & $\begin{array}{l}\text { Growth } \\
\text { chamber }\end{array}$ \\
\hline$\alpha$-Pinene & 2.476 & 0.998 & 0.996 & 0.992 \\
\hline Camphene & 2.875 & 0.993 & 0.994 & 0.976 \\
\hline$\beta$-Pinene & 3.363 & 0.969 & 0.956 & 0.960 \\
\hline$\delta$-3-Carene & 4.010 & 0.789 & 0.652 & 0.627 \\
\hline Myrcene & 4.348 & 0.986 & 0.984 & 0.981 \\
\hline Limonene & 5.073 & 0.808 & 0.983 & 0.969 \\
\hline$\beta$-Phellandrene & 5.236 & 0.976 & 0.972 & 0.958 \\
\hline
\end{tabular}

a Correlations $(r)$ are for trees inoculated with A morphotype isolates $(P<$ 0.001 for all comparisons).

b Total monoterpenes were measured 4 weeks after inoculation. Four treatments were used in the field: no treatment, herbicide to kill surrounding weeds, supplemental water, and both weed removal by herbicide and supplemental water.

c Total monoterpenes were measured 12 days after inoculation. Seedlings were either watered to field capacity daily (nonstressed) or not watered at all (stressed). 
for isolates in both years). The interaction between tree treatment and branch treatment was significant $(P<0.001$ in 1992, and $P=$ 0.012 in 1994), indicating that A and B isolates caused different responses depending on the tree treatment. Differences in monoterpene concentrations among tree treatments were significant only for isolates of morphotype A, on the basis of LSD. Monoterpene concentrations in branches inoculated with isolates of morphotype A were positively correlated with symptom severity $(P<0.001$ for both years; $r=0.831$ in 1992 , and $r=0.913$ in 1994), but correlations were not significant for branches inoculated with isolates of morphotype B.

Although colonization by $S$. sapinea resulted in an increase in the total concentration of monoterpenes, it did not change their relative amounts. The concentrations of individual monoterpenes were highly correlated with total monoterpene in both years $(P<$ 0.001 for all comparisons) (Table 1), indicating little change in monoterpene composition. $\delta$-3-Carene was more variable than the other monoterpenes, but the correlation was still significant at $P<0.001$.

Nine monoterpenes were detected in shoot segments. The concentrations of the most common monoterpenes extracted are summarized for nontreated trees (Table 2). Terpinolene and sabinene were occasionally detected in trace amounts (data not shown), mainly in nontreated trees inoculated with A isolates in 1992 and only in these trees in 1994.

There were no tree treatment or branch treatment effects on the concentrations of total phenolics extracted from trees $(P=0.889$ in 1992 and $P=0.750$ in 1994 for tree treatment; $P=0.071$ in 1992 and $P=0.472$ in 1994 for branch treatment). For nonwounded controls, the mean concentrations of total phenolics were $7.66 \pm$ $0.50 \mathrm{mg} / \mathrm{g}$ (dry weight) in 1992 and $7.65 \pm 0.48 \mathrm{mg} / \mathrm{g}$ in 1994 .

Plant material from the growth chamber. The different watering regimes resulted in differences in $\psi_{\mathrm{PD}}$. Differences between stressed and nonstressed seedlings were significant for all days, except the first reading of trial two. The mean $\psi_{\mathrm{PD}}$ values (all days) for trials one and two, respectively, were $-0.82 \pm 0.07 \mathrm{MPa}$ and $-0.97 \pm 0.13 \mathrm{MPa}$ for stressed seedlings and $-0.47 \pm 0.01$ $\mathrm{MPa}$ and $-0.48 \pm 0.01 \mathrm{MPa}$ for nonstressed seedlings. The lowest mean $\psi_{\mathrm{PD}}$ values (last day of experiment) for stressed seedlings were $-1.13 \pm 0.18 \mathrm{MPa}$ for trial one and $-1.54 \pm 0.24 \mathrm{MPa}$ for trial two.

TABLE 2. Composition ( $\mathrm{mg} / \mathrm{g}$ dry weight \pm standard error) of the monoterpenes of red pine (Pinus resinosa) shoots

\begin{tabular}{|c|c|c|c|c|}
\hline \multirow[b]{2}{*}{ Compound } & \multirow[b]{2}{*}{ A isolates } & \multirow[b]{2}{*}{$\mathrm{B}$ isolates } & \multicolumn{2}{|c|}{ Control } \\
\hline & & & Nonwounded & Wounded \\
\hline \multicolumn{5}{|l|}{$1992^{\mathrm{a}}$} \\
\hline$\alpha$-Pinene & $72.14 \pm 12.01$ & $13.38 \pm 4.26$ & $7.56 \pm 0.98$ & $8.47 \pm 0.48$ \\
\hline$\beta$-Pinene & $18.04 \pm 1.57$ & $4.11 \pm 0.97$ & $1.96 \pm 0.35$ & $2.78 \pm 0.28$ \\
\hline$\delta$-3-Carene & $4.32 \pm 1.70$ & $0.57 \pm 0.20$ & $0.38 \pm 0.15$ & $0.38 \pm 0.11$ \\
\hline Total $^{\mathrm{b}}$ & $98.09 \pm 14.60$ & $18.95 \pm 5.52$ & $10.53 \pm 0.94$ & $12.33 \pm 0.36$ \\
\hline \multicolumn{5}{|l|}{$1994^{\mathrm{a}}$} \\
\hline$\alpha$-Pinene & $45.64 \pm 9.99$ & $7.07 \pm 1.49$ & $6.45 \pm 0.60$ & $7.07 \pm 0.84$ \\
\hline$\beta$-Pinene & $14.17 \pm 2.74$ & $3.58 \pm 0.86$ & $2.76 \pm 0.92$ & $3.95 \pm 0.32$ \\
\hline$\delta$-3-Carene & $1.60 \pm 1.60$ & $0.12 \pm 0.11$ & $0.08 \pm 0.08$ & $0.11 \pm 0.11$ \\
\hline Total $^{\mathrm{b}}$ & $63.83 \pm 13.71$ & $11.40 \pm 2.28$ & $9.95 \pm 1.42$ & $11.89 \pm 1.13$ \\
\hline \multicolumn{5}{|c|}{ Growth chamber } \\
\hline$\alpha$-Pinene & $32.21 \pm 3.77$ & & $10.23 \pm 0.55$ & $10.61 \pm 0.53$ \\
\hline$\beta$-Pinene & $8.20 \pm 0.90$ & $\cdots$ & $1.64 \pm 0.21$ & $1.77 \pm 0.10$ \\
\hline$\delta$-3-Carene & $2.10 \pm 0.41$ & & $0.28 \pm 0.06$ & $0.38 \pm 0.05$ \\
\hline Total $^{\mathrm{b}}$ & $44.61 \pm 4.99$ & $\ldots$ & $13.00 \pm 0.73$ & $13.64 \pm 0.66$ \\
\hline
\end{tabular}

a Monoterpenes were measured 4 weeks after inoculation. Results are for trees with no tree treatment.

${ }^{\mathrm{b}}$ Total includes, from most to least common, $\alpha$-pinene, $\beta$-pinene, $\delta$-3-carene, $\beta$-phellandrene, myrcene, limonene, and camphene.

${ }^{\mathrm{c}}$ Monoterpenes were measured 12 days after inoculation. Seedlings were either watered to field capacity daily (nonstressed) or not watered at all (stressed). Results are the combined means for both watering regimes.
Watering regime influenced the amount of resin flow from the site of inoculation (Table 3). Inoculated, nonstressed seedlings produced more resin from wounds than stressed seedlings. The flow of resins beyond the wound was rarely observed for control seedlings of either watering regime.

Inoculated seedlings that were water stressed developed necrotic needles at greater distances below the inoculation site than nonstressed seedlings $(2.5 \pm 0.3 \mathrm{~cm}$ on stressed seedlings and 0.9 $\pm 0.2 \mathrm{~cm}$ on nonstressed seedlings for both isolates). Three-factor analysis of variance of symptom severity after 12 days indicated effects of watering regime $(P<0.001)$ and inoculation treatment $(P<0.001)$ but not of trial $(P=0.084)$. The interaction between inoculation treatment and watering regime was significant $(P<$ 0.001 ), suggesting that isolates responded differently to different watering regimes.

Total monoterpene concentrations varied in response to inoculation treatment, shoot segment, and interaction between inoculation treatment with shoot segment $(P<0.001$ for all comparisons). Monoterpene concentrations were higher in inoculated shoots than in control shoots and were higher in inoculated shoots closer to the site of inoculation (Fig. 2). Tests for effects of watering regime $(P=0.780)$, trial $(P=0.383)$, interaction of watering regime with inoculation treatment $(P=0.828)$, and interaction of shoot segments with watering regime $(P=0.858)$ were not significant. Monoterpene concentrations in inoculated shoots were positively correlated with symptom severity $(P<0.001 ; r=0.654)$. Shoots of control seedlings from the growth chamber had total monoterpene concentrations similar to those of control shoots from the plantation.

Colonization by $S$. sapinea resulted in an increase in the total concentration of monoterpenes but did not change their relative amounts. As in the field experiment, the concentrations of individual monoterpenes were highly correlated with total monoterpene ( $P<0.001$ for all comparisons) (Table 1$)$, indicating that little change in monoterpene composition occurred. $\delta$-3-Carene was the most variable of the monoterpenes, yet the correlation was significant at $P<0.001$.

The same nine monoterpenes detected in the field experiment were detected in this experiment. The concentrations of the most common monoterpenes extracted are summarized for all seedlings (Table 2). Trace amounts of terpinolene and sabinene were also

TABLE 3. Number of observations ${ }^{\mathrm{a}}$ in three resin flow categories ${ }^{\mathrm{b}}$ for red pine (Pinus resinosa) seedlings inoculated with the A morphotype of Sphaeropsis sapinea and either water stressed or well watered

\begin{tabular}{|c|c|c|c|c|c|}
\hline \multirow[b]{2}{*}{ Watering regime $^{\mathrm{c}}$} & \multirow{2}{*}{$\begin{array}{c}\text { Inoculation } \\
\text { treatment }\end{array}$} & \multicolumn{3}{|c|}{ Resin flow categories } & \multirow[b]{2}{*}{$P^{\mathrm{d}}$} \\
\hline & & Low & Moderate & High & \\
\hline \multirow[t]{3}{*}{ Nonstressed } & A1 & 1 & $\underline{4}^{\mathrm{e}}$ & $\underline{5}$ & \\
\hline & $\mathrm{A} 2$ & 1 & $\overline{2}$ & $\underline{7}$ & \\
\hline & Wounded control & $\underline{7}$ & $\underline{3}$ & $\overline{0}$ & \\
\hline \multirow[t]{3}{*}{ Stressed } & A1 & $\overline{7}$ & $\overline{2}$ & 1 & \\
\hline & $\mathrm{A} 2$ & $\underline{6}$ & $\underline{4}$ & 0 & \\
\hline & Wounded control & $\underline{8}$ & $\overline{2}$ & 0 & $<0.001$ \\
\hline
\end{tabular}

a Values are the total number of seedlings from two growth chamber trials each having five seedlings per treatment. Young shoots were inoculated by placing colonized agar plugs on wounds made by removing needle fascicles.

${ }^{b}$ Resin flow from the wound was visually estimated 12 days after inoculation and ranked as low (no resin off the wound), moderate (resin less than $3 \mathrm{~mm}$ from the wound), or high (resin $3 \mathrm{~mm}$ or more from the wound).

c Seedlings were either watered daily (nonstressed) or never watered (stressed).

d Probability that there is no difference among resin flow categories, based on Fisher's exact test.

e Underlined numbers indicate observed frequencies higher than expected, although they may not indicate significant differences. The expected frequencies used were $(S \times C) / N$, where $S$ is the number of observations for a combined inoculation and water treatment, $C$ is the total number of observations in the resin flow category of interest, and $N$ is the total number of observations. 
detected but only occasionally in seedlings inoculated with A isolates (data not shown).

Inoculated seedlings produced higher concentrations of phenolics near the inoculation sites (Fig. 3). Differences in concentrations of total phenolics extracted from shoots were significant for inoculation treatment $(P=0.011)$ and shoot segments $(P=0.001)$ but not for watering regime $(P=0.329)$. For nonwounded controls, the mean concentrations of total phenolics were $9.61 \pm 0.80$ $\mathrm{mg} / \mathrm{g}$ (dry weight) in the 6 -cm segment closer to the shoot apex and $7.01 \pm 0.71 \mathrm{mg} / \mathrm{g}$ in the $6-\mathrm{cm}$ segment farther from the shoot apex. Shoots of control seedlings from the growth chamber had total phenolic concentrations similar to those of control shoots from the plantation.

\section{DISCUSSION}

The complex chemistry of coniferous trees has long been recognized. Some chemicals, including monoterpenes and phenolics, are present in relatively high concentrations, accumulate in response to wounding and pathogen invasion, and can have static or toxic effects in vitro. These facts have led to speculation that these chemicals are involved in the restriction of pathogen infection and colonization of hosts. Although these chemicals may be involved in the restriction of pathogens, results of our studies revealed no evidence linking either concentration or composition of monoterpenes or concentration of phenolics with host resistance to the more varietal A morphotype isolates of $S$. sapinea on droughtstressed red pines. The relatively high concentrations of monoterpenes measured and the fact that water-stressed trees were more severely colonized than nonstressed trees do not support the hypothesis that these chemicals restrict pathogen colonization of drought-stressed red pines by isolates of $S$. sapinea morphotype A.

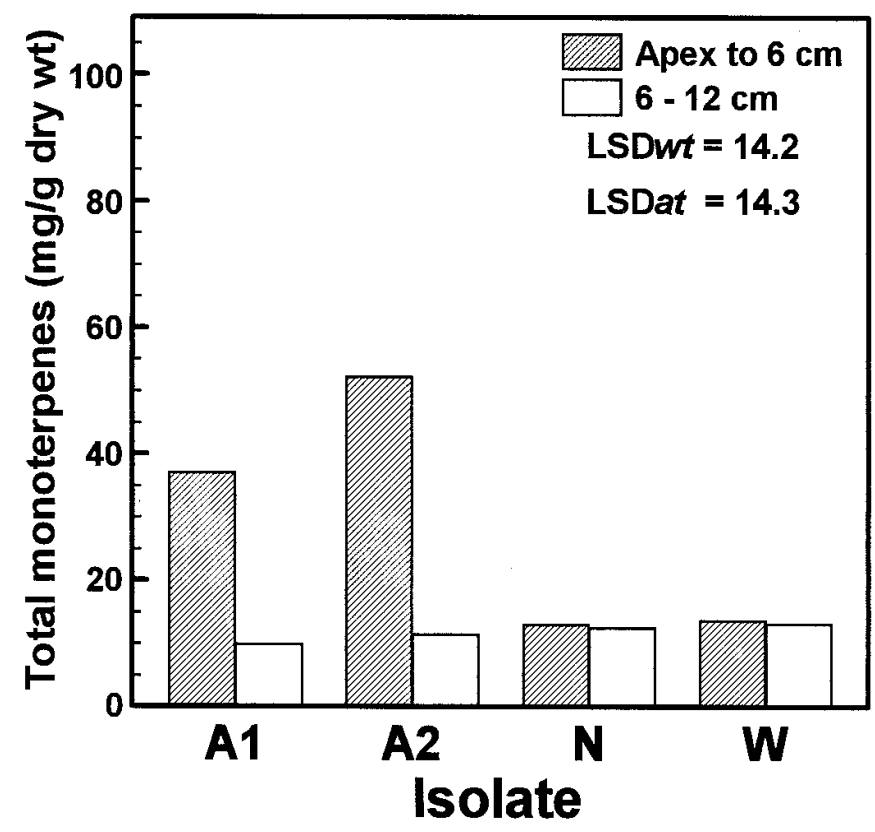

Fig. 2. Total monoterpenes measured 12 days after inoculation. Growth chamber-grown red pine (Pinus resinosa) seedlings were nonwounded $(\mathrm{N})$ or wounded (W) and inoculated with sterile agar plugs or with plugs colonized by two Sphaeropsis sapinea isolates. Results of different watering regimes were combined because no differences were observed for watering regime $(P=0.329)$. Shoot segments were analyzed at two distances from the apex. Values are combined means of two separate trials with 10 seedlings per treatment in each trial. LSD = Fisher's least significant differences for separating the means at $P=0.05$. LSD wt is used for means within a treatment combination at different distances from the inoculation site. LSDat is used for means across treatment combinations.
The reduced resin flow from wound sites on water-stressed seedlings compared with that on nonstressed seedlings in this study is consistent with a general response of conifers to water stress. This has been noted previously for other species of Pinus and for species of Abies and Pseudotsuga (13). If resin or its components have physical or chemical roles in restricting colonization by pathogens, effects might be limited in trees in which water stress restricts resin production, accumulation, or transport.

Mechanical damage has been reported to result in increased concentrations of monoterpenes $(24)$ and phenolics $(19,27)$ around wounds. In our study, however, wounding alone did not affect concentrations of monoterpenes and phenolics. Our inoculation method was intended to provide a uniform wound that exposed (by cutting through a leaf trace) the xylem and phloem to $S$. sapinea while producing relatively little damage to the stem. The relatively mild wounding procedure used in these experiments, compared with that used in previous studies, may explain our results. Care should be taken, therefore, in generalizing about wounding as a stimulus for elevation of monoterpene and phenolic concentrations.

Water stress also has been reported to cause increases in total monoterpene concentration and changes in relative monoterpene composition. These effects have been noted for needles of Norway spruce (Picea abies (L.) H. Karst.) (21), for xylem oleoresin of loblolly pine (Pinus taeda L.) (18), and for other conifers (13). In contrast, our study did not reveal any effects of water stress on monoterpene concentration or composition in uninoculated tissue. The lack of significant effects might be the result of the realistic but relatively moderate levels of water stress used in our experiments. The lack of a significant effect on phenolic concentrations in our experiments, however, is consistent with previous studies (13), which failed to demonstrate any definite trend in the rela-

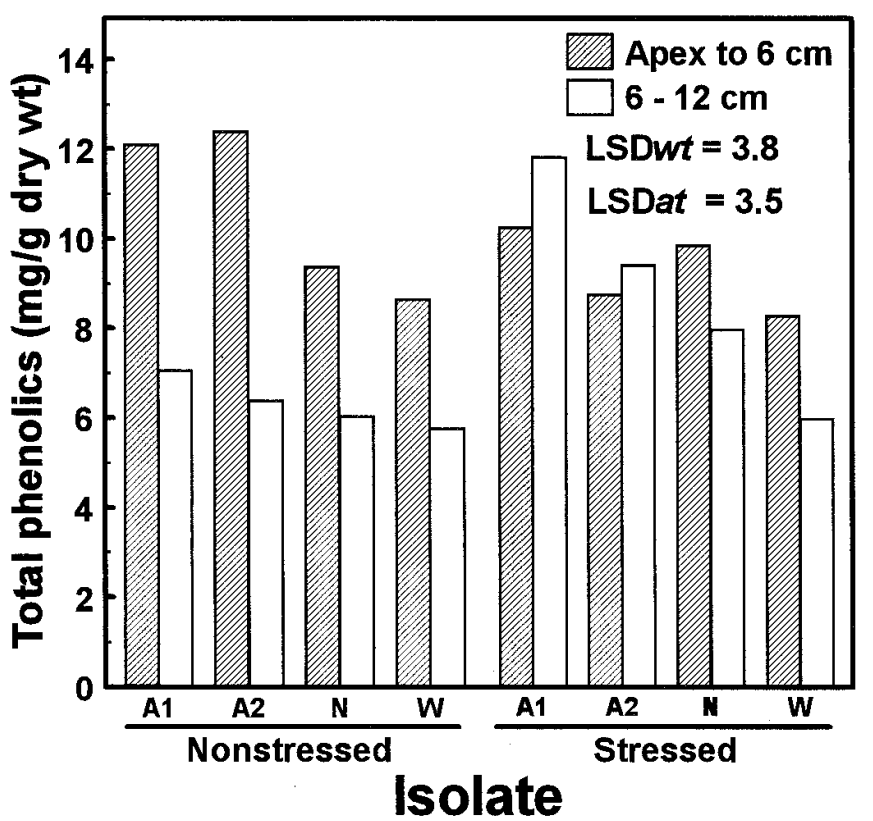

Fig. 3. Total phenolic compounds measured 12 days after inoculation. Growth chamber-grown red pine (Pinus resinosa) seedlings were nonwounded $(\mathrm{N})$ or wounded $(\mathrm{W})$ and inoculated with sterile agar plugs or with plugs colonized by two Sphaeropsis sapinea isolates. Seedlings were either watered daily (nonstressed) or not at all (stressed). Shoot segments were analyzed at two distances from the apex. Values are combined means of two separate trials with five seedlings per treatment combination in each trial. LSD $=$ Fisher's least significant differences for separating the means at $P=0.05$. LSD $w t$ is used for means within a treatment combination at different distances. LSDat is used for means across treatment combinations. 
tionship between water stress and concentrations of these compounds.

Although water stress did not affect the concentration of monoterpenes or phenolics in red pine shoots in uninoculated tissue, stress did affect the concentration of monoterpenes if $S$. sapinea isolates of morphotype A were present. Inoculation with isolates of morphotype B resulted in little or no symptom expression and no changes in monoterpene concentration. Several different results, however, indicate that the enhancement of monoterpene and phenolic concentrations is the result of interaction with the more aggressive A isolates. Monoterpene concentrations in shoots inoculated with isolates of morphotype A were higher than those in control shoots in both experiments. In the growth chamber experiment, monoterpene concentrations in the shoot segments that included the inoculation sites (colonized tissues) were higher than in segments farther from the inoculation sites (noncolonized tissues). In the segments farther from the inoculation sites, monoterpene concentrations were similar to those in control shoots. Similarly, phenolic concentration in the shoot segments closer to the inoculation sites was higher than in those segments farther from the inoculation sites for the nonstressed seedlings. Finally, although direct comparison of results from inoculation with isolates of morphotype $\mathrm{A}$ in the two experiments is not possible, trees in the field (which were challenged for a longer period and had greater lengths of shoots colonized by the pathogen) yielded greater concentrations of monoterpenes than seedlings in the growth chamber.

Our results do not support the idea that monoterpenes and phenolics are involved in a water potential-dependent restriction of red pine colonization by aggressive isolates of $S$. sapinea. Their concentrations were not responsive to water potential in the absence of the pathogen, and high concentrations of these compounds were not associated with restriction of the A isolates. Tolerance levels of decay and stain fungi to these chemicals, however, have been shown to vary among species $(10,17)$. Similarly, although both monoterpenes $(6,9)$ and a phenolic (6) inhibit spore germination and mycelial growth of $S$. sapinea in vitro, responses vary by morphotype. Isolates of the $\mathrm{B}$ morphotype are more sensitive than those of the A morphotype (6). The relative ability of $\mathrm{A}$ isolates to tolerate these compounds might help to explain differences in aggressiveness between isolates of the $S$. sapinea morphotypes.

\section{ACKNOWLEDGMENTS}

We thank W. Livingston and D. Smith for presubmission review, anonymous reviewers, M. Clayton for statistical advice, the Wisconsin Department of Natural Resources for seedlings, M. Palmer for cultures, and K. Raffa for suggestions. We also thank D. Smith, M. Guthmiller, F. Kirschling, G. Sandhu, S. Ludwig, R. Caldwell, L. Covert, S. Birren, A. Lekies, and J. Schwarz for technical assistance and J. Trobaugh, J. Cappel, and J. Bagley from Georgia-Pacific Corporation. The partial financial support of the USDA (Hatch) and Georgia-Pacific Corporation is gratefully acknowledged.

\section{LITERATURE CITED}

1. Bachi, P. R., and Peterson, J. L. 1985. Enhancement of Sphaeropsis sapinea stem invasion of pines by water deficits. Plant Dis. 69:798-799.

2. Birch, T. T. C. 1936. Diplodia pinea in New Zealand. N.Z. For. Serv. Bull. 8.

3. Blanchette, R. A., and Biggs, A. R. 1992. Defense Mechanisms of Woody Plants Against Fungi. Springer-Verlag, Berlin.

4. Blodgett, J. T., Kruger, E. L., and Stanosz, G. R. 1997. Effects of moderate water stress on disease development by Sphaeropsis sapinea on red pine. Phytopathology 87:422-428.

5. Blodgett, J. T., Kruger, E. L., and Stanosz, G. R. 1997. Sphaeropsis sapinea and water stress in a red pine plantation in central Wisconsin. Phytopathology 87:429-434.

6. Blodgett, J. T., and Stanosz, G. R. 1997. Differential inhibition of Sphaeropsis sapinea morphotypes by a phenolic compound and several monoterpenes of red pine. Phytopathology 87:606-609.

7. Blodgett, J. T., and Stanosz, G. R. 1997. Sphaeropsis sapinea morphotypes differ in aggressiveness, but both infect nonwounded red or jack pines. Plant Dis. 81:143-147.

8. Chou, C. K. S. 1987. Crown wilt of Pinus radiata associated with Diplodia pinea infection of woody stems. Eur. J. For. Pathol. 17:398-411.

9. Chou, C. K. S., and Zabkiewicz, J. A. 1976. Toxicity of monoterpenes from Pinus radiata cortical oleoresin to Diplodia pinea spores. Eur. J. For. Pathol. 6:354-359.

10. De Groot, R. C. 1972. Growth of wood-inhabiting fungi in saturated atmospheres of monoterpenoids. Mycologia 64:863-870.

11. Entry, J. A., Cromack, K., Jr., Hansen, E., and Waring, R. 1991. Responses of western coniferous seedlings to infection by Armillaria ostoyae under limited light and nitrogen. Phytopathology 81:89-94.

12. Franich, R. A., Gaskin, R. E., Wells, L. G., and Zabkiewicz, J. A. 1982. Effect of Pinus radiata needle monoterpenes on spore germination and mycelial growth of Dothistroma pini in vitro in relation to mature tree resistance. Physiol. Plant Pathol. 21:55-63.

13. Gershenzon, J. 1984. Changes in the levels of plant secondary metabolites under water and nutrient stress. Recent Adv. Phytochem. 18:273320 .

14. Gibbs, J. N. 1968. Resin and the resistance of conifers to Fomes annosus. Ann. Bot. 32:649-665.

15. Hawksworth, D. L., Kirk, P. M., Sutton, B. C., and Pegler, D. N. 1995. Ainsworth and Bisby's Dictionary of the Fungi. 8th ed. C.A.B. International Mycological Institute, Egham, England.

16. Hergert, H. L. 1960. Chemical composition of tannins and polyphenols from conifer wood and bark. For. Prod. J. 10:610-617.

17. Hintikka, V. 1970. Selective effect of terpenes on wood-decomposing Hymenomycetes. Karstenia 11:28-32.

18. Hodges, J. D., and Lorio, P. L., Jr. 1975. Moisture stress and composition of xylem oleoresin in loblolly pine. For. Sci. 21:283-290.

19. Jorgensen, E. 1961. The formation of pinosylvin and its monomethyl ether in the sapwood of Pinus resinosa Ait. Can. J. Bot. 39:1765-1772.

20. Julkunen-Tiitto, R. 1985. Phenolic constituents in the leaves of northern willows: Methods for the analysis of certain phenolics J. Agric. Food Chem. 33:213-217.

21. Kainulainen, P., Oksanen, J., Palomäki, V., Holopainen, J. K., and Holopainen, T. 1992. Effect of drought and waterlogging stress on needle monoterpenes of Picea abies. Can. J. Bot. 70:1613-1616.

22. Kelsey, R. G., and Harmon, M. E. 1989. Distribution and variation of extractable total phenols and tannins in the logs of four conifers after 1 year on the ground. Can. J. For. Res. 19:1030-1036.

23. Kennedy, R. W. 1956. Fungicidal toxicity of certain extraneous compounds of Douglas-fir heartwood. For. Prod. J. 6:80-84.

24. Klepzig, K. D., Kruger, E. L., Smalley, E. B., and Raffa, K. F. 1995. Effects of biotic and abiotic stress on induced accumulation of terpenes and phenolics in red pines inoculated with bark beetle-vectored fungus. J. Chem. Ecol. 21:601-626.

25. Klepzig, K. D., Smalley, E. B., and Raffa, K. F. 1996. Combined chemical defenses against an insect-fungal complex. J. Chem. Ecol. 22:13671388.

26. Laughton, F. S. 1937. The incidence of fungal disease on timber trees in South Africa. S. Afr. J. Sci. 33:377-382.

27. Lieutier, F. 1993. Induced defence reaction of conifers to bark beetles and their associated Ophiostoma species. Pages 225-233 in: Ceratocystis and Ophiostoma: Taxonomy, Ecology, and Pathogenicity. M. J. Wingfield, K. A. Seifert, and J. F. Webber, eds. American Phytopathological Society, St. Paul, MN.

28. Lieutier, F., and Berryman, A. A. 1988. Preliminary histological investigations of the defense reactions of three pines to Ceratocystis clavigera and two chemical elicitors. Can. J. For. Res, 18:1243-1247.

29. Madar, Z., Solel, Z., and Kimchi, M. 1989. Effect of water stress in cypress on the development of cankers caused by Diplodia pinea $\mathrm{f}$. sp. cupressi and Seiridium cardinale. Plant Dis. 73:484-486.

30. Milliken, G. A., and Johnson, D. E. 1993. Analysis of Messy Data. Vol. 1, Designed Experiments. Chapman and Hall, London.

31. Nebeker, T. E., Hodges, J. D., and Blanche, C. A. 1993. Host response to bark beetle and pathogen colonization. Pages 157-173 in: Beetle-Pathogen Interactions in Conifer Forests. T. D. Schowalter and G. M. Filip, eds. Academic Press, San Diego, CA.

32. Nicholls, T. H., and Ostry, M. E. 1990. Sphaeropsis sapinea cankers on stressed red and jack pines in Minnesota and Wisconsin. Plant Dis. 74:54-56.

33. Palmer, M. A. 1991. Isolate types of Sphaeropsis sapinea associated with main stem cankers and top-kill of Pinus resinosa in Minnesota and Wisconsin. Plant Dis. 75:507-510.

34. Palmer, M. A., Stewart, E. L., and Wingfield, M. J. 1987. Variation among 
isolates of Sphaeropsis sapinea in the north central United States. Phytopathology 77:944-948.

35. Raffa, K. F. 1991. Induced defensive reactions in conifer-bark beetle systems. Pages 245-276 in: Phytochemical Induction by Herbivores. D. W. Tallamy, ed. John Wiley \& Sons, New York.

36. Raffa, K. F., and Steffeck, R. J. 1988. Computation of response factors for quantitative analysis of monoterpenes by gas-liquid chromatography. J. Chem. Ecol. 14:1385-1390.

37. Scholander, P. F., Hammel, H. T., Edda, D., Bradstreet, E. D., and Hemmingsen, E. A. 1965. Sap pressure in vascular plants. Science 148:339346.
38. Shain, L. 1967. Resistance of sapwood in stems of loblolly pine to infection by Fomes annosus. Phytopathology 57:1034-1045.

39. Shrimpton, D. M. 1973. Extractives associated with wound response of lodgepole pine attack by the mountain pine beetle and associated microorganisms. Can. J. Bot. 51:527-534.

40. Wattermann, J. L., Gleason, M. L., Bradford, E., Iles, J. K., and Flynn, P. H. 1993. Effect of preinoculation and postinoculation water stress on stem invasion of Scots pine by Sphaeropsis sapinea. (Abstr.) Phytopathology 83:1410.

41. Whitney, R. D., and Denyer, W. B. G. 1969. Resin as a barrier to infection of white spruce by heartrotting fungi. For. Sci. 15:266-267. 